6th International Conference on Industrial Engineering and Industrial Management.

XVI Congreso de Ingeniería de Organización. Vigo, July 18-20, 2012

\title{
Economic Analysis of the Renewable Energy Policies in the European Union
}

\section{Roberto Rodríguez, Carlos Rodríguez-Monroy; Miguel Ángel Peláez}

Abstract: The European energy sector is undergoing a major transformation and is facing a series of difficult challenges. These include a high and increasing dependence on external energy resources; dramatically reduce the need for the emissions of greenhouse gases to meet environmental objectives and the difficulties related to the promotion of energy market effectively integrated and competitive. Some of the policies associated with the various objectives are sometimes in conflict with each other, while in other cases are mutually reinforcing. The aim of this paper is to do a scientific analysis of the developments so far and the expectations for the coming period focusing on the pillars of energy policy in the EU in terms of security of supply, environment, climate change and promoting a competitive and integrated market. The use of renewable energy sources is seen as a key element of European energy policy and should help to: reduce dependence on fuel from non-member countries; reduce emissions from carbon-based energy sources, and; decouple energy costs from oil prices.

Keywords: Energy policy, Economic development, Management, Renewable energy, Security of Supply

\subsection{Energy Policies in the European Union}

In January 2007, the European Commission adopted a Communication proposing a new energy policy for Europe, with the goal of combating climate change and boosting the EU's energy security and competitiveness through the development of a more sustainable and low-carbon economy. Based on the European Commission's proposal, the European Council endorsed the following targets in March 2007, namely, to:

\footnotetext{
${ }^{1}$ Roberto Rodriguez ( $\left.\square\right) \quad$ C. Rodriguez-Monroy

Departamento de Ingeniería de Organización, Administracion de Empresas y Estadistica. Escuela Tecnica Superior de Ingenieros Industriales. Universidad Politecnica de Madrid C/ Jose Gutierrez Abascal 2, 28006. Madrid, Spain

e-mail: roberto.rodriguez.rosado@alumnos.upm.es
} 
a reduction in greenhouse gas emissions, the diversification of energy supplies and a reduced dependency on fossil fuel markets (in particular, oil and gas). The growth of renewable energy sources may also have the potential to stimulate employment in Europe, through the creation of jobs in new 'green' technologies.

The primary production of renewable energy within the EU in 2008 was 148.1million tons of oil equivalents (toe) - a17.6\% share of total primary energy production (Eurostat \& Commission, 2009). The volume of renewable energy produced within theEU-27 increased overall by $57.0 \%$ between 1998 and 2008, equivalent to an average increase of $4.6 \%$ per year. Among renewable energies, the most important source in the EU was biomass and waste, accounting for 69.1 $\%$ of primary renewable production in 2008 . Hydropower was the other main contributor to the renewable energy mix (19.0\% of the total).

Although its level of production remains relatively low, there was a particularly rapid expansion in the output of wind energy, which accounted for $6.9 \%$ of the EU's renewable energy produced in 2008. The largest producer of renewable energy within the EU in 2008 was Germany, with a $20.1 \%$ share of the EU total; France $(13.4 \%)$ and Sweden $(10.8 \%)$ were the only other countries to record a double-digit share. There were considerable differences in the renewable energy mix across the member States, which reflected to a large degree natural endowments and climatic conditions. For example, more than three quarters $(75.7 \%)$ of the renewable energy produced in Cyprus was from solar energy, while more than a third of the renewable energy in the relatively mountainous countries of Austria, Slovenia and Sweden was from hydropower(much higher shares were recorded in Norway and Switzerland). More than one third of the renewable energy production in Italy was from geothermal energy sources (where active volcanic processes still exist); this share rose to more than $80 \%$ in Iceland.

The output of renewable energy in Germany grew at an average rate of 13.6 \%per year between 1998 and 2008, as such its share of the EU-27 total rose by 11.2percentage points from an $8.8 \%$ share in1998. There were also average growth rates in excess of $10 \%$ per year recorded for Belgium, Hungary and the Czech Republic, where the fastest growth in renewable energy production was recorded, averaging14.2 \% per year between 1998 and 2008.Renewable energy sources accounted for $8.4 \%$ of the EU's gross inland energy consumption in 2008.

The EU seeks to have a $20 \%$ share of its energy consumption from renewable sources by 2020; this target is broken down between the Member States with national action plans designed to plot a pathway for renewable energies in each country. The share of renewable in gross final energy consumption stood at 10.3 \%in the EU in 2008, almost half the target that has been set for 2020.

Among the member States, the highest share of renewable in gross final energy consumption in 2008 was recorded in Sweden (44.4\%), while Finland and Austria each reported more than a quarter of their final energy consumption derived from renewable. Compared with the most recent data available for 2008, the indicative targets for Denmark, Ireland, Greece, France, Italy, Latvia, the Netherlands and the United Kingdom require each of these countries to increase their share of renewable sin final energy consumption by at least 10 percentage points. 


\subsubsection{Electricity}

Directive 2001/77/EC set indicative targets for the production of electricity from renewable energy sources: according to these, $21 \%$ of the EU's gross electricity consumption should be sourced from renewable by 2010. The latest information available for 2008 shows that electricity generated from renewable energy sources contributed $16.7 \%$ of the EU-27'sgross electricity consumption. In Austria (62.0 $\%)$ and Sweden (55.5\%) more than half of all the electricity consumed was generated from renewable energy sources, largely as a result of hydropower and biomass.

Across the member States, only Germany and Hungary had already surpassed their indicative targets for 2010 by 2008; Belgium, Denmark, the Netherlands and Finland were each within a single percentage point of attaining their targets. The growth in electricity generated from renewable energy sources during the period1998 to 2008 largely reflects an expansion in two renewable energy sources; namely, wind turbines and biomass. Although hydropower remained the single largest source for renewable electricity generation in the EU in 2008, the amount of electricity generated was somewhat lower than a decade earlier $(-2.6$ $\%)$. In contrast, the volume of electricity generated from biomass increased by 244 $\%$, while that from wind turbines rose by $953 \%$.

\subsubsection{Transport}

At the end of 2008, the EU agreed to set a target for each Member State, such that renewable energy sources (including biofuels, hydrogen or 'green' electricity)should account for at least $10 \%$ of all fuel used within the transport sector by 2020.The average share of renewable energy sources across the EU was $3.5 \%$ in 2008,ranging from a high of $7.1 \%$ in Austria, and more than $6 \%$ in Sweden, Slovakia and Germany, to less than $1 \%$ in Latvia(Eurostat yearbook 2011).The share of renewable in gross final energy consumption may be considered as an estimate for the purpose of monitoring Directive 2009/28/EC on the promotion of the use of energy from renewable sources; note, the statistical system for some renewable energy technologies is not yet fully developed to meet the requirements of this Directive.

Electricity from renewable energy sources is defined as the ratio between electricity produced from renewable energy sources and gross national electricity consumption. Electricity produced from renewable energy sources comprises electricity generation from hydropower plants (excluding pumping), as well as electricity generated from biomass/wastes, wind, solar and geothermal installations. The share of renewable energies in the fuel consumed by the transport sector is calculated on the basis of energy statistics, according to the methodology as described in Directive 2009/28/EC. Note, the contribution of all biofuels is currently 
included within the calculation for this indicator and that the data are not restricted to biofuels satisfying the sustainability criteria.

Directive 2009/28/EC of the European Parliament and Council on the promotion of the use of energy from renewable sources set an overall goal across the EU-27 for a $20 \%$ share of energy consumption to be derived from renewable sources by 2020, while renewable should also account for a $10 \%$ share of the fuel used in the transport sector by the same date. The Directive changes the legal framework for promoting renewable electricity, requires national action plans to show how renewable energies will be developed in each Member State, creates cooperation mechanisms, and establishes sustainability criteria for biofuels (following concerns over their potential adverse effects on crop prices, food supply, forest protection, biodiversity, water and soil resources).

\subsection{Future Perspectives}

After analysing all these studies, it appears that despite the European Union framework has been implemented from the famous White Paper of 1997; energy policy remains a local matter and not an issue at the level of the community. So, it is necessary to introduce it into the policies of the union: a) support for technology b) establishment of objectives in the medium and long term, and c) provide the boundary conditions (like a system for guarantees of origin). Actual incentives for market penetration of renewable energy were hardly present.

A good way for the European Union to continue its objectives and given the times in which we are, lies in the fact that we must not reduce the budget to support European policies for the implementation of renewable energy, of course, without forgetting the future changes that will occur in the European institutions as a result of the crisis. In the proposed constitution for the European Union, makes clear that energy policy; there will be a shared competence call: "and both the Union and Member States have the power to legislate and adopt legally binding acts in that area. The member States shall exercise their competence to the extent that the Union has not exercised, or has decided to cease exercising, its competence" (Commission, European Convention, 2003). This makes it likely that policy initiatives for the implementation of renewable will be more and more taken at the Union level.

How would a future common system of renewable energy support look like? It is most likely that, -for the short term, -national support systems, including feedin tariffs and tax exemptions, are still needed. However, such policies cannot be free of commitment from the side of the governments. Continuity of policies is an important prerequisite for effectiveness. As the market for renewable energy is gradually becoming more mature, it might be necessary to let the support system gradually evolve to a European support system based on renewable energy obligations and tradable green certificates (Nielsena \& Jeppesen, 2003). But in the short and medium term continuity seems to be more important than speed as several problems will be encountered. 
If we consider briefly the main challenges that represent the three basic pillars for the future, and what you can do to solve European energy policy, we find that:

1. With regard to energy dependence and security of supply in the European market there is a clear need to diversify the energy mix where possible and efficient, both in terms of different types of energy as different geographical sources. Greater reliance on domestic energy resources (such as renewable and nuclear) will help reduce both dependence on foreign, and to promote the objective changes related to climate change. This reinforces the idea that Europe supports to some extent domestic energy sources, given the characteristics of "public good" that are both energy security and climate change and especially the use of renewable energy sources given the future perspectives that have (Commission, Energy efficiency in buildings, 2010). However, in the medium term, the energy market remains dependent on gas as a key source of flexible and relatively clean energy, to enable an efficient transition to an environment of low CO2 (where the new nuclear energy, clean coal, and renewable energy generation will play a larger role). Inevitably, this means that security of supply and energy dependence will remain a key issue in the optimal design of the EU energy policy in the near future.

2. On the other hand referring to imports of energy, that Europe should diversify its mix of suppliers and reduce its dependence on certain countries (especially Russia). Also, the new strategic players such as China and India play an important role in this regard and now the market is global and therefore the competition is global.

3. Greater reliance on intermittent generation sources (such as renewable) will create new challenges in terms of domestic security of supply, both in electricity and in oil or gas. The periods of insufficient generation of renewable energy will create strong demand peaks generation which will require a major boost for the interconnection of Europe. In the words of Andris Piebalgs, member of the European Energy Commission: "Climate change and energy security are two sides of the same coin" (Piebalgs, 2009). So will have to meet these peaks and that will require greater investment in network infrastructure, so as to guarantee delivery and security.

4. As regards climate change and related policies, data and projections that we have discussed in this article illustrate the fact that the energy market in the next 10-20 years will face a major transformation to meet the objectives required. Given the proposed environmental objectives need to ask how they can optimally be met in order to reduce the costs of reducing CO2 (and, possibly, de-carbonization of the sector). The discussion about the best policies to achieve environmental objectives raises a number of questions and challenges as: What should promote clean technologies to minimize the overall costs of reducing $\mathrm{CO} 2$ emissions, and how soon (given the necessity to reduce emissions gradually over a long period of time)? We should take into account that there are technologies that are less established and have a higher yield than oth- 
ers, such as wind energy above photovoltaic solar energy. Moreover, what is the best way to encourage low-emission technologies, without the owners of these technologies and who developed excessive obtain income, while providing sufficient incentives to invest in alternative sources? We can see that in some of the renewable energies, since the tariffs are regulated and the system operator is obliged to buy the energy produced, they are some imbalances in the market.

\subsection{Conclusions}

In summary, we believe that it should promote a common energy policy, given the externalities between countries of the EU (energy mix and environment), the necessary investments in new technologies, the need to be able to negotiate with supplier countries, and the convenience of having a single international voice of the EU on this matter. Another key aspect of the EU's energy policy is to constrain consumption by promoting energy efficiency, both within the energy sector itself and among end-users. These policies are designed to bring about a new industrial revolution that will result in a low-energy economy, whilst making the energy consumed more secure, competitive and sustainable, with the goal of the EU becoming a world leader in renewable energy and low-carbon technologies. The European energy sector will have to undertake a profound transformation if you want to meet the objectives.

\subsection{References}

Commission, E. (2003). European Convention.

Commission, E. (2007). Energy Policy for the European Union. (COM 2007_1).

Commission, E. (2010, Mayo 19). Energy efficiency in buildings. Directiva 2010/31/CE.

(n.d.). Eurostat yearbook 2011.

Eurostat, \& Commission, E. (2009). Eurostat yearbook 09.

Nielsena, L., \& Jeppesen, T. (2003). Tradable green certificates in selected European Countries. Piebalgs, A. (2009, November). Energy Security in th EU. Eufocus. 